\title{
Hyaluronan injection in murine osteoarthritis prevents TGFbeta 1-induced synovial neovascularization and fibrosis and maintains articular cartilage integrity by a CD44-dependent mechanism
}

Jun $\mathrm{Li}^{1 \dagger}$, Daniel J Gorski ${ }^{2 \dagger}$, Wendy Anemaet ${ }^{1,3}$, Jennifer Velasco ${ }^{2}$, Jun Takeuchi ${ }^{4}$, John D Sandy ${ }^{2}$ and Anna Plaas ${ }^{1,2^{*}}$

\begin{abstract}
Introduction: The mechanism by which intra-articular injection of hyaluronan (HA) ameliorates joint pathology is unknown. Animal studies have shown that HA can reduce synovial activation, periarticular fibrosis and cartilage erosion; however, its specific effects on the different cell types involved remain unclear. We have used the TTR (TGFbeta1 injection and Treadmill Running) model of murine osteoarthritis (OA), which exhibits many OA-like changes, including synovial activation, to examine in vivo tissue-specific effects of intra-articular HA.
\end{abstract}

Methods: The kinetics of clearance of fluorotagged HA from joints was examined with whole-body imaging. Naîve and treated knee joints were examined macroscopically for cartilage erosion, meniscal damage and fibrosis. Quantitative histopathology was done with Safranin O for cartilage and with Hematoxylin \& Eosin for synovium. Gene expression in joint tissues for Acan, Col1a1, Col2a1, Col3a1, Col5a1, Col10a1, Adamts5 and Mmp13 was done by quantitative PCR. The abundance and distribution of aggrecan, collagen types I, II, III, V and X, ADAMTS5 and MMP13 were examined by immunohistochemistry.

Results: Injected HA showed a half-life of less than $2 \mathrm{~h}$ in the murine knee joint. At the tissue level, HA protected against neovascularization and fibrosis of the meniscus/synovium and maintained articular cartilage integrity in wild-type but not in Cd44 knockout mice. HA injection enhanced the expression of chondrogenic genes and proteins and blocked that of fibrogenic/degradative genes and proteins in cartilage/subchondral bone, whereas it blocked activation of both groups in meniscus/synovium. In all locations it reduced the expression/protein for Mmp13 and blocked Adamts 5 expression but not its protein abundance in the synovial lining.

Conclusions: The injection of HA, $24 \mathrm{~h}$ after TGFbeta1 injection, inhibited the cascade of OA-like joint changes seen after treadmill use in the TTR model of OA. In terms of mechanism, tissue protection by HA injection was abrogated by $\mathrm{Cd} 44$ ablation, suggesting that interaction of the injected HA with CD44 is central to its protective effects on joint tissue remodeling and degeneration in OA progression.

\footnotetext{
* Correspondence: Anna_Plaas@rush.edu

+ Contributed equally

'Department of Internal Medicine (Rheumatology), Rush University Medical

Center, 1611 West Harrison Street Suite 510, Chicago, IL 60612, USA

Full list of author information is available at the end of the article
} 


\section{Introduction}

The generally accepted, albeit limited, benefit of hyaluronan (HA) injection for patients with osteoarthritis (OA) [1] has been accompanied by basic research, initiated in about 1996 [2], to unravel the mechanism(s) of this effect. Studies in OA models in rats, rabbits, dogs and sheep have indicated that HA has pleitrophic effects, such as antiapoptotic, anti-inflammatory, anti-angiogenic and antifibrotic. For example, HA treatment of rats after joint immobilization [3] or intra-articular IL-1 injection [4] protects against cartilage degeneration, apparently due to both anti-apoptotic and anti-inflammatory effects. Moreover, OA-like changes after ovine anterior cruciate ligament transection (ACLT) or meniscectomy include fibrosis and neovascularization of the synovium, and this pathology is also ameliorated by HA injections $[5,6]$. In the same context, extended strenuous uphill running of rats [7] results in a fibrous deposition in the infrapatellar fat pad and this is prevented by HA injection during the exercise period. These inhibitory effects of HA on fibroplasia in animal joint tissues appear to be very relevant to human treatments since human OA has been associated with activation of pro-fibrogenic genes in cartilage $[8,9]$ and overt fibrosis of the synovium [10-12], subchondral bone $[13,14]$ and vastus medialis muscle [15]

We have reported that for mice, intra-articular injections of TGFbeta1 prior to treadmill running (TTR model) results in mechanically-induced fibrotic remodeling and erosion of the articular cartilage as well as synovial hyperplasia and fibrosis [16]. Notably, these pathologies did not develop in ADAMTS5-deficient mice, apparently because the absence of ADAMTS5 can prevent TGFbeta1-induced fibrogenesis (via Smad2/3), and promote TGFbeta1/BMPinduced chondrogenesis (via Smad1/5/8), a switch which has been demonstrated in newborn fibroblasts [17] and bone marrow derived mesenchymal stem cells (MSCs) (Gorski D and Plaas A, unpublished). Further, the chondrogenic effect of Adamts 5 ablation in dermal fibroblasts in vivo was shown to be eliminated, and fibrogenic pathways activated by concomitant ablation of $C d 44$ [17].

Our primary goal in the current work was to use this murine model of OA to determine whether HA injection abrogates the fibrogenic cell and tissue changes which occur in the synovium/meniscus and cartilage/subchondral bone compartments in this model. As part of this objective we also studied the effect of HA injection on the expression and abundance of the two metalloproteases, ADAMTS5 and MMP13, which are now primarily invoked to explain tissue degeneration in murine and human OA [18]. In addition, studies in isolated chondrocytes and synoviocytes [19-22] have suggested a role for CD44 in HA-mediated inhibition of expression of MMP1/ 13 and ADAMTS4/5 by these cell types. To determine whether CD44 might also be required for the effects of HA in vivo, we have used Cd44-/- mice in the TTR model of OA.

\section{Materials and methods}

\section{Osteoarthritis model and experimental groups}

The murine TTR (TGFbeta1 injection plus Treadmill Running) model is described in detail elsewhere [16] and also summarized in Figure 1A. Male mice (wild type and Cd44-/- strains [17] in the C57BL/6 background, age 12 weeks) were bred in-house, and all animal protocols were approved by the Rush University Medical Center Animal Care and Use Committee. HA or saline injections were given one day after the second TGFbeta1 injection, and the effect was studied for acute changes and longer term changes (see Figure 1A for group names). For the acute study, the groups included: a) untreated mice (Naïve), b) mice sacrificed two days after the second TGFbeta1 injection without further treatment (Acute), and c) mice sacrificed one day after HA injection (Acute $+\mathrm{HA}$ ). For the longer-term study, the three groups were: a) mice sacrificed on Day 19 after the two TGFbeta1 injections and 14 days treadmill running (TTR), b) mice sacrificed on Day 19 after TGFbeta1 treatment, HA injection and 14 days of treadmill running (TTR+HA) and mice sacrificed on Day 19 after TGFbeta1 treatment, saline injection and 14 days of treadmill running (TTR+SA). For the study with $C d 44-/-$ mice, the groups analyzed were Naive, TTR and TTR+HA.

\section{Hyaluronan preparations, intra-articular delivery and dwell time}

HA (Supartz, Seikagaku Co., Tokyo, Japan 620-1170 kDa, average $900 \mathrm{kDa}$ ) was diluted with sterile saline and $7.5 \mathrm{ug}$ in $10 \mathrm{ul}$ was injected through the patellar ligament into the joint space of the right knee with a 30-gauge needle on an insulin syringe. Fluorescein isothiocyanate (FITC)labeled HA [23] was chromatographed on Sephacryl S-1000 (GE Healthcare Biosciences, Piscataway, NJ, USA) in $0.1 \mathrm{M}$ sodium acetate, $\mathrm{pH} 7.0$ [24] and the eluant monitored for fluorescence. Essentially all of the fluorescence was in high molecular weight HA (absorbance at $214 \mathrm{~nm}$, A214) as shown by exclusion from the gel (Figure 1A). To check the accuracy of injection and the dwell time of HA in the joint, the FITC-labeled HA was injected into the knee of naïve mice $(n=4)$ and also mice which had been injected into the knee $24 \mathrm{~h}$ earlier with $200 \mathrm{ng}$ active TGFbeta1 $(n=4)$. At $0,2,5$ and $18 \mathrm{~h}$, mice were placed in a Kodak FX System (Carestream Health Inc., Rochester, NY, USA) for X-ray and fluorescence analysis. Accuracy of injection was confirmed (Figure 1C) and the bulk of the injected HA were eliminated (from both naïve and TGFbeta1 injected joints) in the first $2 \mathrm{~h}$, although traces 


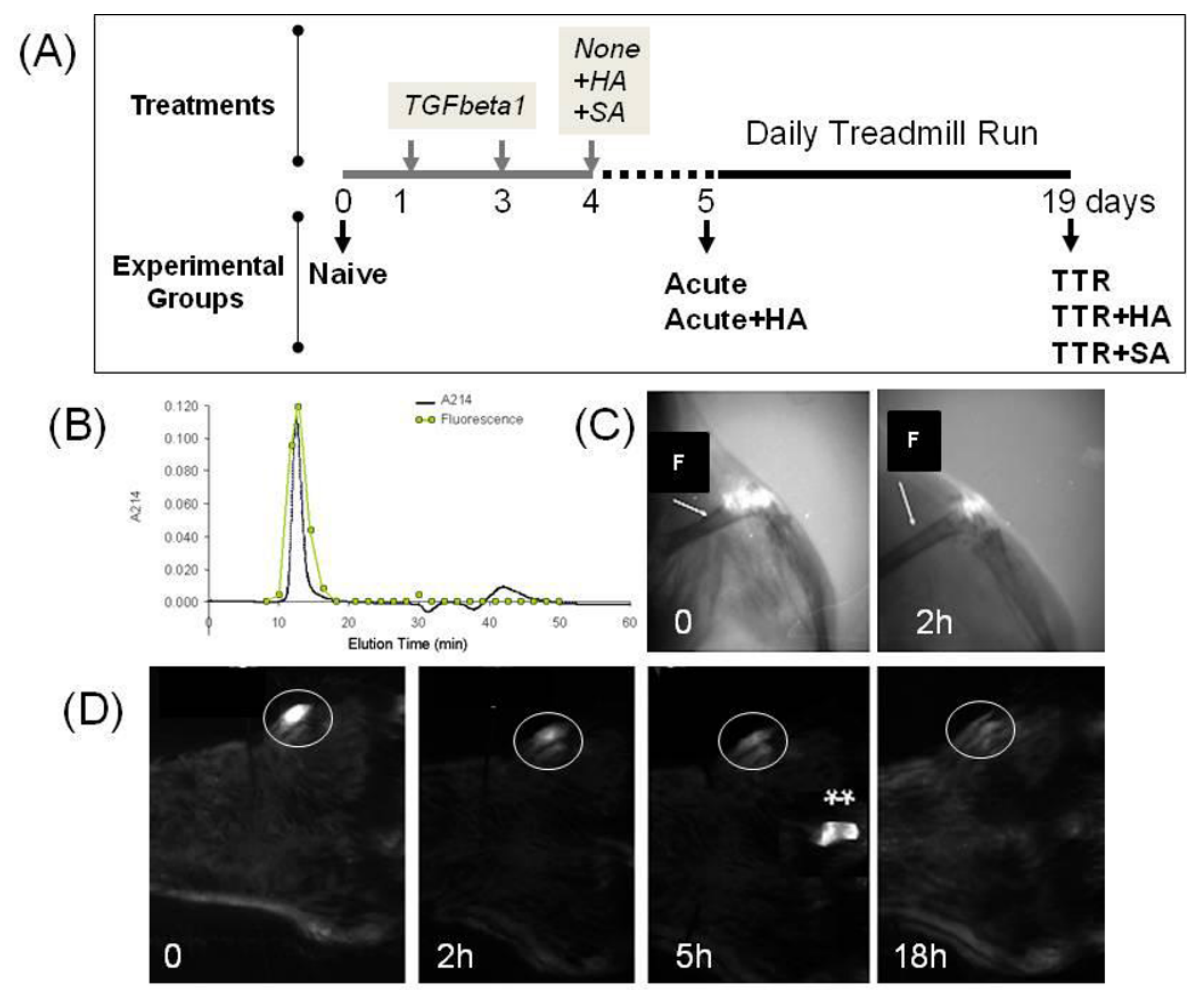

Figure 1 Experimental protocols and elimination of HA from the murine knee joint. (A) The schematic shows details of the time line for intraarticular injections, treadmill running and time points for tissue collection. (B) Characterization of FITC-labeled HA preparation (620 to 1,170 kDa) by Sephacryl S-1000 chromatography. (C) Fluorescence imaging and x-ray analyses of joints shows accuracy of delivery of FITC-labeled HA into the joint space. (F, Femur) (D) Whole body fluorescent imaging was used to determine the time course of disappearance from the joint of FITC-labeled HA (FITC labeled excretory products at $5 \mathrm{~h}$ after injection are indicated by ${ }^{* *}$ ). Procedures are described in detail in the Methods section.

could be detected at $18 \mathrm{~h}$ (Figure 1D). High fluorescence was also seen in the urethra at $5 \mathrm{~h}$ (Figure 1D), probably derived from the short-lived HA pool released from the joint in the first $2 \mathrm{~h}$.

\section{Macroscopic imaging and histopathology}

Global joint pathology [25] was evaluated by India Ink application followed by surface photography under a Nikon dissecting microscope (SMZ1000, X6) (Nikon Instruments Inc., Melville, NY, USA). Abnormalities were evaluated blindly, paying particular attention to the deposition of fibrotic tissue around the menisci and along the medial and lateral aspects of the tibial plateau, femoral condyles and patella groove margins, and any evidence of an associated cartilage surface roughening or erosion (see Figure 2). The reproducibility and discriminatory power of macroscopic evaluation was established earlier [25,26]; however, scoring was not used here because of the obvious and marked effects of HA on global pathology, histopathology and immunohistochemistry.

For histology, intact mouse knees were dissected away from the skin, fixed with $10 \%$ neutral buffered formalin for a minimum of three days, and decalcified in 5\% ethylenediaminetetraacetic acid (EDTA)/phosphate-buffered saline (PBS) for three weeks. Specimens were paraffin embedded and about 180 thin sections (6 um) were taken across the entire joint from medial to lateral in the sagittal plane. Slides 1 to 30,31 to 60 and 61 to 90 (two adjacent sections per slide) spanned the medial, central groove and lateral compartments, respectively. For histopathological assays, deparaffinized slides 1, 11, $21,31,41,51,61,71$ and 81 were stained with Safranin $\mathrm{O}$ and slides $2,12,22,32,42,52,62,72$, and 82 were stained with hematoxylin/eosin.

The mean stainable cartilage in joints from each experimental group was determined as follows: the area (tibia plus femur) of Safranin $\mathrm{O}$ positive tissue was obtained by visual tracing (see Figure $3 \mathrm{~A}$ ), coupled to the area function of the NIH image analysis software Image J (Bethesda, MD, USA). Areas were determined on each of 32 equally spaced sagittal sections taken across the lateral compartment of the right joint of each mouse. The total area for each mouse was the summed area values of the 32 sections. The mean total area (+/-SD) (cartilage 


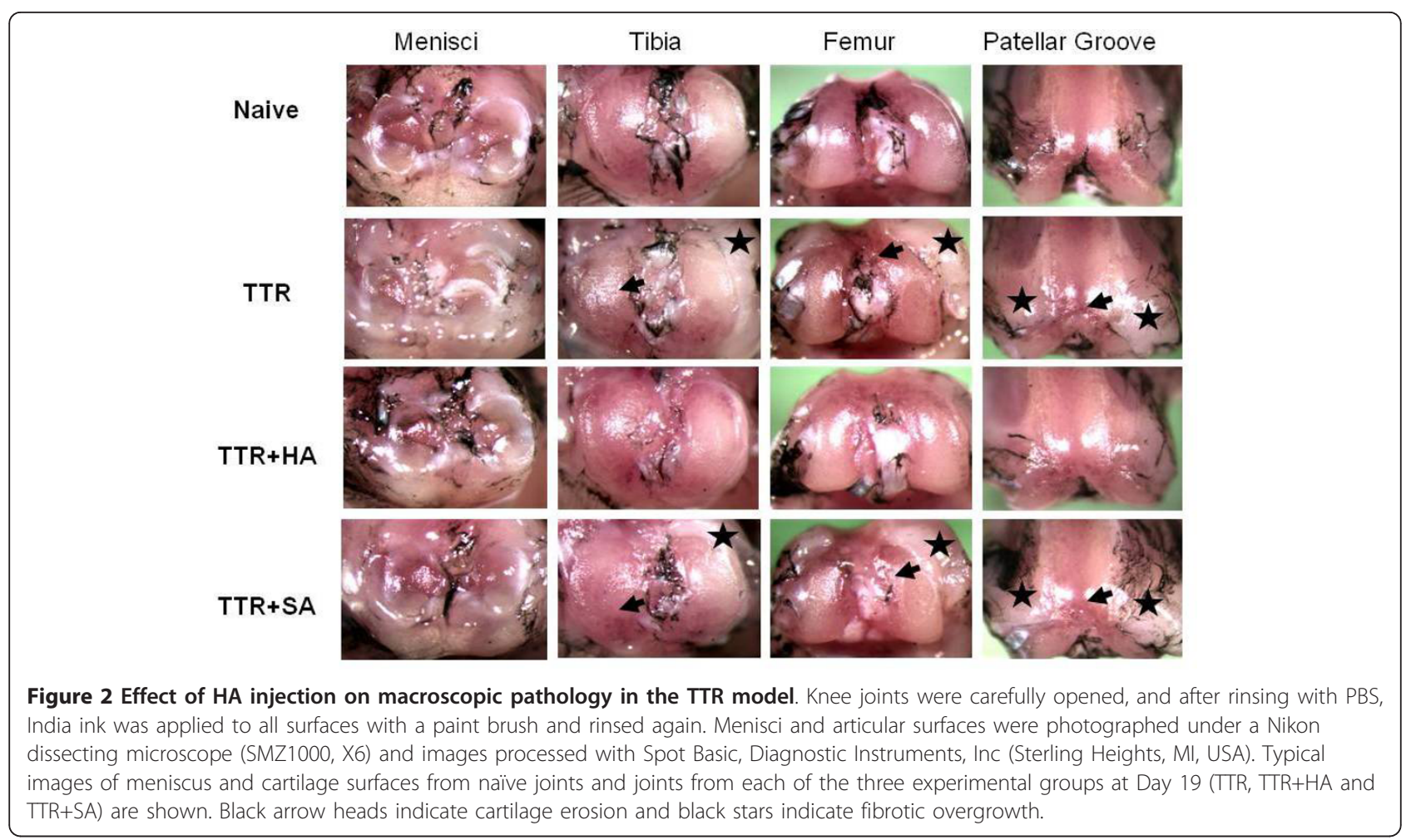

volume (arbitrary units) on Figure 3B) was calculated from the total area for each mouse $(N=6)$ in each group.

Synovial histopathology was scored essentially as described [5] on a scale of 0 to 5 for sub intimal fibrosis and for vascularity. The analysis was done on 16 equally spaced sagittal sections from the lateral compartment of each joint stained with hematoxylin/eosin, and only matching regions of the proximal and distal perimeniscal synovium were scored. The mean score for fibrosis or vascularity for each mouse was the sum of the scores from the 16 sections divided by 16 . The mean scores $(+/-\mathrm{SD})$ for fibrosis or vascularity in each group $(N=4)$ were calculated from the mean score from each mouse in the group.
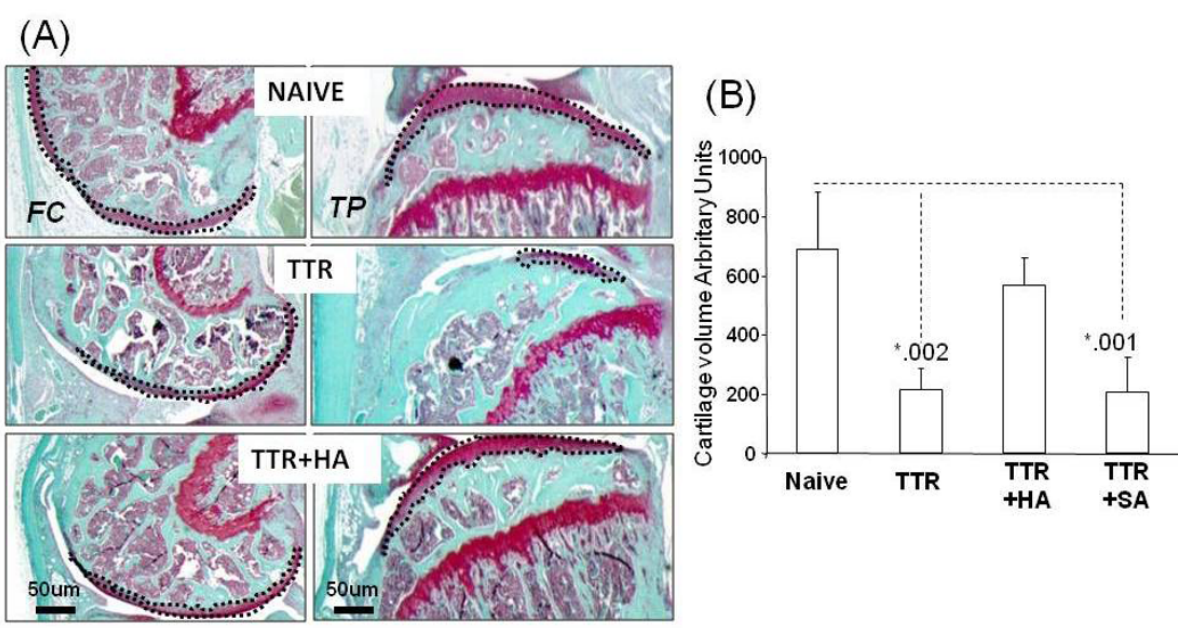

Figure 3 Effect of HA injection on cartilage histopathology in the TTR model. (A) Typical Safranin O histology of femoral and tibial epiphyses from naïve joints and joints of TTR and TTR+HA groups (B). For each of the experimental groups, the mean (+/SD) cartilage volume was calculated from the area stained with Safranin $\mathrm{O}$ as described in the Methods. The dotted lines show typical selections of areas used for cartilage quantitation. 


\section{Quantitative PCR}

A total of 16 naïve mice and 24 experimental mice for each treatment group (TTR, TTR $+\mathrm{HA}$ and TTR $+\mathrm{SA}$ ) were analyzed as follows: articular surfaces from two mice were combined for each assay and these pools $(n=8$ to 12) were analyzed separately. Cartilage-rich tissue was pooled from tibial and femoral surfaces by a fine scalpel cut across the surfaces. Histological inspection showed that all cartilage samples contained subchondral bone, but no growth plate cartilage, so that these samples are described as cartilage/subchondral bone throughout. The menisci and synovial tissue were harvested. This was done by making a circular incision along the synovium/periarticular attachments on the medial and lateral tibial plateaus, followed by cutting the anterior and posterior attachments of both menisci. For menisci/synovial tissue analysis, two tissue pools from each experimental group were prepared, with each derived from 8 to 12 mice. This was necessitated by the relatively low content/yield of mRNA from meniscus/synovium relative to cartilage/subchondral bone samples.

All specimens were harvested into RNALater and stored at $-20 \mathrm{C}$ before analyses. RNA was prepared by thawing tissues on ice, rinsing with fresh RNALater (Qiagen, Valencia, CA, USA), snap-freezing in liquid nitrogen and pulverizing, prior to application of the PerfectPure RNA Kit for Fibrous Tissue (5 PRIME). Taqman-based QPCR (Life Technologies, Carlsbad, CA, USA) was done with inventoried primers for mouse Acan, Col3a1 and Adamts5 as described [17]. Primers for Col1a1, Col5a1, Col10a1, and Mmp13 were Mm00801666_g1, Mm00489342_m1, Mm004 87041_m1 and Mm00439491_m1, respectively. QPCR values of meniscus/synovium used for comparisons between experimental groups were the average of the data from the two pools, with the difference between the results being $<20 \%$ of the average pool value.

\section{Immunohistochemistry}

Anti-collagen type I (ab34710), anti-collagen type II (ab34712), anti-collagen type III (ab7778), anti-collagen type V (ab7046), anti-collagen type $\times(\mathrm{ab} 58632)$ and antiMMP13 (ab75606) were purchased from Abcam UK (Cambridge, MA, USA). Aggrecan and ADAMTS5 were detected as described [27] using anti-DLS and anti-KNG respectively. For each joint, the two sections on slides 3 to 10,13 to 20,23 to 30,63 to 70,73 to 80 and 83 to 90 were taken for immunohistochemistry. Briefly, deparaffinized sections were incubated in primary antibodies or nonimmune IgG (both $10 \mathrm{ug} / \mathrm{ml}$ ) overnight at $4^{\circ} \mathrm{C}$. Sections to be stained with anti-MMP13, anti-ADAMTS5, anticollagen type $\mathrm{X}$ and anti-collagen type II were digested with proteinase $\mathrm{K}$ to obtain optimal antigen exposure. Sections were next incubated with biotinylated goat antirabbit IgG, HRP-labeled avidin-biotin complex and 3, 3'- diaminobenzidine substrate. Nuclei and cartilage matrix were counter-stained with methyl green as described by Vector Labs, Burlingame, CA, USA. It should be noted that this IHC staining procedure predominantly stained antigens in the pericellular/cell-associated space and that antigen retrieval procedures, such as proteinase $\mathrm{K}$, chondroitinase or hyaluronidase pretreatment, but did not significantly enhance general matrix staining. Further, all antibodies were shown to exhibit high specificity as determined with controls employing only the secondary antibody. Since the differences in signal intensity and distribution (with multiple antibodies on multiple sections) between treatment groups were highly reproducible and clearly biologically relevant, no scoring system or statistical evaluation was developed for this analysis.

\section{Statistical analysis}

For those experiments where data were obtained separately from six or more individual mice $(\mathrm{N}>5)$, two-way ANOVA for independent samples was used as an initial analysis, followed by Students $t$-test for comparisons between the most relevant pairs of groups. For menisci/ synovial tissue no statistical analysis was applied.

\section{Results}

\section{Effect of HA injection on macroscopic pathology and cartilage loss in the TTR Model}

A schematic describing the time line of the model, treatment for each experimental group and tissue harvest points is shown in Figure 1A. The macroscopic pathology seen on the surfaces of menisci, tibia, femur and the patellar groove in the TTR model (Figure 2, Row 2), relative to the appearance of naive joints (Figure 2, Row 1), is shown. As described previously $[16,25]$ in this model, there is a deposition of fibrotic tissue around the menisci and along the medial and lateral aspects of the tibial plateau, femoral condyles and patella groove margins, which is most likely derived from activation of synovium and periosteum by TGFbeta1 injection. Furthermore, this remodeling is commonly associated with cartilage surface roughening or erosion.

The effects of HA injection (TTR+HA) relative to saline injection (TTR+SA) is illustrated in the two bottom rows. When HA was injected on Day 4 after the TGFbeta1 but before treadmill running (Figure 2, TTR + HA group), a marked protection against the development of these overgrowths and cartilage erosion at all sites was observed. However, when saline was injected instead of HA (Figure 2, TTR+SA) there was no protective effect on macroscopic pathology.

To further evaluate cartilage protective effects of intraarticular HA injection in the TTR model, Safranin Ostained histological sections were prepared from the knees of six mice from each of the naive, TTR and TTR $+\mathrm{HA}$ 
groups. Typical images of the femoral and tibial surfaces are provided in Figure 3A. The TTR group generally showed thinner and less intensely stained cartilage than the naïve and TTR+HA groups, consistent with the macroscopic findings. When the mean volume of cartilage in the knee joints of mice from the four different groups (Naïve, TTR, TTR+HA and TTR+SA) was estimated by SafraninO staining (see Methods), the TTR model resulted in an approximately $70 \%$ loss of cartilage compared to naïve mice $(P=0.002)$ and injection of HA (TTR+HA) largely prevented this loss, whereas with injection of saline (TTR+SA) the loss remained $(P=0.001)$ (Figure 3B).

\section{Effect of HA injection on acute and long-term histopathological changes in perimeniscal synovium}

The effect of HA on the response of synovial tissue to TGFbeta1 (Acute) and TTR was also studied, with four mice in each treatment group, and typical H/E-stained sections from both sets are shown in Figure 4A. A cellular hyperplastic response $(\mathrm{H})$ of both lining and stromal cells was induced by TGFbeta1 injection alone (Acute) and HA injection (Acute $+\mathrm{HA}$ ) had little or no effect on this early process. After treadmill running, the synovium exhibited extensive fibrotic deposits $(\mathrm{F})$ and these were also frequently populated by multiple blood vessels (V). HA injection (TTR+HA) essentially prevented the fibrotic response in the stromal region and the lining, blocked the vascular response and restored the adipocyte-rich naive appearance of the stroma. When naive mice were run on the treadmill for two weeks there was no sign of changes in the perimeniscal synovium (not shown). To provide quantitative data on these effects between the different treatment groups, we applied a multi-parameter scoring system (see Methods) to each section and the mean $+/$-SD data $(N=4)$ are provided on Figure 4B. This showed clearly that injection of HA on Day 4 essentially prevented the appearance of fibrotic remodeling and vascular changes by Day 19 , whereas saline injection was ineffective in this regard.

\section{Effect of HA injection on expression of chondrogenic and fibrogenic genes in cartilage/subchondral bone}

Our previous studies of this model showed that alterations in macroscopic, chondrogenic and fibrotic tissue responses most readily explained the effects of Adamts5 ablation [16] and HA injection [25]; however, we did not assess specific cellular responses in those studies. Here we have determined expression levels of the chondrogenic genes Acan, Col2a1 and Col10a1 and the fibrogenic genes Col1a1, Col3a1 and Col5a1 in all experimental groups (Naive, Acute, TTR, TTR+HA and TTR+SA) with the tissues separated into cartilage/subchondral bone and meniscus/ synovium. This showed that TGFbeta1 injection alone

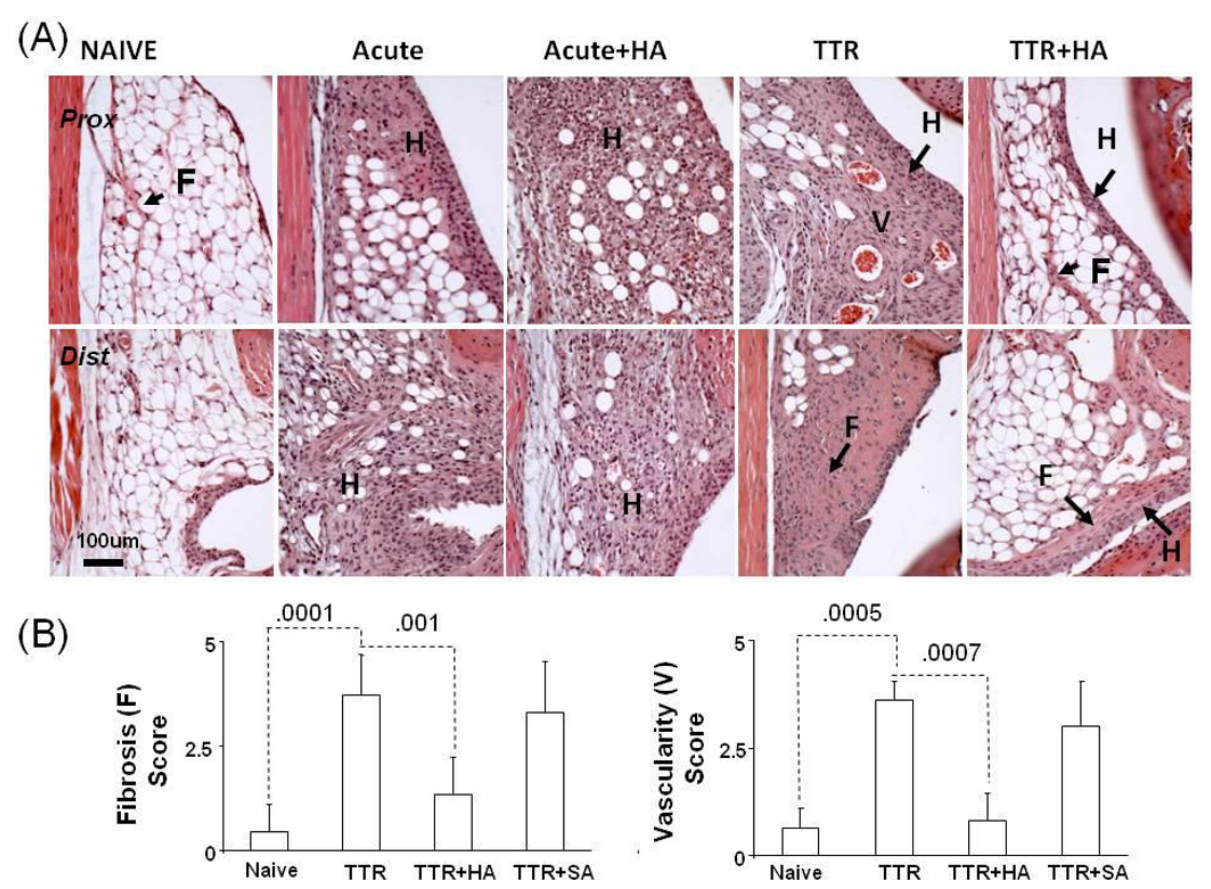

Figure 4 Effect of injection of HA on synovial histology at Day 4 and Day 19 of model. (A) Typical images of proximal (Prox) and distal (Dist) regions of the perimeniscal synovium from Hematoxylin\&Eosin stained sections are shown for five experimental groups (Naïve, Acute, Acute+ HA, TTR and TTR+HA). Histological changes were identified as: hyperplasia (H), fibrosis (F) and neovascularization (V). (B) Mean pathology scores for fibrosis (F) and vascularization ( $V$ ) were obtained from 16 stained sections per mouse $(n=4$ mice for each of the four experimental groups Naive, TTR, TTR+HA, TTR+SA) and statistical analysis performed as described in the Methods section. 
increased the cartilage/subchondral bone expression of Acan (2.39-fold) and Col2a1 (5.77-fold), whereas Col10a1 was essentially unaffected (Table 1 ). The increased expression of Acan and Col2a1 was normalized somewhat after the complete TTR, but it was activated, beyond the levels seen with TGFbeta1 alone, in the TTR+HA group. TGFbeta1 injection alone also increased the expression of Col1a1, Col3a1 and Col5a1 by 36.5 -fold, 2.97 -fold and 2.80 -fold, respectively (Table 2 Acute). With TGFbeta1 injection and treadmill running (TTR) the high level of Colla1 expression at Day 5 (Acute group) was maintained, and Col3a1 and Colsa1 expression was further stimulated to 13.2-fold and 17.9-fold relative to naive levels. Injection of HA (TTR+HA) returned Col1a1, Col3a1 and Col5a1 expression to near naive levels, whereas injection of saline (TTR+SA) did not markedly affect the enhancement of fibrogenic gene expression seen in TTR. Taken together, the data in Tables 1 and 2 show that a single injection of HA on Day 4 of the TTR model (see Figure 1A) maintains chondrogenic gene expression to Day 19, and also markedly reduces the high level of fibrogenic gene expression seen at this time without HA injection.

\section{Effect of HA injection on chondrogenic and fibrogenic proteins in cartilage/subchondral bone}

To confirm translation into protein of the chondrogenic genes (Acan, Col2a1, and Col10a1) and fibrogenic genes (Col1a1, Col3a1, Col5a), immunohistochemistry was performed on 12 sections from different sagittal planes of the right lateral tibial compartment of each mouse and typical results are shown in Figure 5. In general agreement with the gene expression data, TGFbeta1 injection alone (Figure 5A, Acute) did not markedly alter the number or location of chondrocytes which were stained for aggrecan, collagen type II and collagen type X. For the TTR group, the degenerated cartilage (note roughened surface) contained cells which were not stained, and also those which were intensely stained in the pericellular/ cell-associated space, for aggrecan, collagen type II and collagen type $\times[28]$. Notably, cells staining for these chondrogenic proteins were also frequently seen in the calcified cartilage and subchondral bone regions in all experimental groups that had received TGFbeta1 injections. In the TTR+HA group, the cartilage surfaces remained largely intact and appeared similar to naïve cartilage. However, the underlying chondrocytes showed greatly enhanced pericellular/cell-associated staining for aggrecan when compared to naïve cartilage, a result which is in keeping with the 3.27-fold increase in Acan gene expression in cartilage/subchondral bone samples from HA treated joints (Table 1).

As suggested by the gene expression data, TGFbeta1 injection alone also increased the proportion of chondrocytes with pericellular/cell-associated staining for collagen types I, III and V, most of them localized in groups in the mid zone of the articular cartilage (Figure 5B, Acute). Consistent with high gene expression levels for the TTR group, strong staining for collagen types I and III (and to some extent collagen type V) was almost exclusively localized to cells at the surface of the lesions and in the surrounding matrix, whereas chondrocytes in the deeper layers and the calcified cartilage showed only minimal staining for the fibrogenic collagens. Notably, and consistent with the gene expression data, HA injection (Figure $5 \mathrm{~B}, \mathrm{TTR}+\mathrm{HA}$ ) was accompanied by cell groups which stained for collagen types I, III and V in the protected articular cartilages. Their presence in the mid zone suggests that they represent those cells which were activated by TGFbeta1 in the acute phase.

\section{Effect of HA injection on expression of chondrogenic and} fibrogenic genes in meniscus/synovium

Injection of TGFbetal alone resulted in a robust activation (up to 40-fold) of all three chondrogenic genes in the meniscus/synovium (Table 3 Acute), which is in marked contrast to the minimal effect of TGFbeta1 on chondrogenic genes in cartilage/subchondral bone (Table 1 Acute). This difference may be explained by proliferation of stromal cells in the synovial lining (see Figure 4) together with their TGFbeta1-induced differentiation towards a chondrogenic phenotype [29]. For the TTR group, (Table 3 TTR), expression of the three

Table 1 QPCR of chondrogenic gene expression in cartilage/subchondral bone

\begin{tabular}{|c|c|c|c|c|c|c|c|c|c|}
\hline & $\begin{array}{l}\text { acan } \\
\Delta \mathrm{CT}^{1}\end{array}$ & $P$ & Fold $^{4}$ & $\begin{array}{l}\text { col2a } \\
\Delta \mathrm{CT}^{1}\end{array}$ & $P$ & Fold $^{4}$ & $\begin{array}{r}\text { col102a } \\
\Delta C T^{1}\end{array}$ & $P$ & Fold $^{4}$ \\
\hline Naive & $3.84(0.30)$ & & 1.00 & $4.29(0.25)$ & & 1.00 & $6.33(0.08)$ & & 1.00 \\
\hline Acute & $2.58(0.04)$ & $.0001^{2}$ & 2.39 & $1.76(0.38)$ & $.0001^{2}$ & 5.77 & $6.74(0.39)$ & $N S^{2}$ & 0.75 \\
\hline TTR & $3.59(0.34)$ & $N S^{2}$ & 1.90 & $2.82(0.60)$ & $.0014^{2}$ & 2.77 & $6.59(0.42)$ & $N S^{2}$ & 0.83 \\
\hline TTR+HA & $2.13(0.24)$ & $.0001^{3}$ & 3.27 & $0.86(0.19)$ & $.0003^{3}$ & 10.7 & $4.82(0.30)$ & $.0001^{3}$ & 2.85 \\
\hline$T T R+S A$ & $3.36(0.03)$ & $N S^{3}$ & 1.40 & $2.32(0.4)$ & $N S^{3}$ & 3.92 & $6.16(0.43)$ & $N S^{3}$ & 1.12 \\
\hline
\end{tabular}

${ }^{1}$ relative to GAPDH, mean (SD) $\triangle C T$ of 8 pools with 2 mice per pool for Naïve and 12 pools with 2 mice per pool for all 4 treatment groups.

$P$-values: ${ }^{2}$ Acute or TTR vs Naive; ${ }^{3} \mathrm{TTR}+\mathrm{HA}$ or $\mathrm{TTR}+\mathrm{SA}$ vs $\mathrm{TTR}$;

${ }^{4}$ Fold Changes are relative to Naive

NS, not significant 
Table 2 QPCR of fibrogenic gene expression in cartilage/subchondral bone

\begin{tabular}{|c|c|c|c|c|c|c|c|c|c|}
\hline & $\begin{array}{l}\text { col1a } \\
\Delta C T^{1}\end{array}$ & $P$ & Fold $^{4}$ & $\begin{array}{r}\text { col3a } \\
\Delta \mathrm{CT}^{1}\end{array}$ & $P$ & Fold $^{4}$ & $\begin{array}{l}\text { col5a } \\
\Delta \mathrm{CT}^{1}\end{array}$ & $P$ & Fold $^{4}$ \\
\hline Naive & $-0.84(0.23)$ & & 1.00 & $6.67(0.17)$ & & 1.00 & $9.98(0.36)$ & & 1.00 \\
\hline Acute & $-6.03(0.29)$ & $<.0001^{2}$ & 36.5 & $5.10(0.71)$ & $.003^{2}$ & 2.97 & $8.50(0.41)$ & $.012^{2}$ & 2.80 \\
\hline TTR & $-6.02(1.03)$ & $<.0001^{2}$ & 36.2 & $2.95(0.44)$ & $.0001^{2}$ & 13.2 & $5.82(1.02)$ & $.001^{2}$ & 17.9 \\
\hline $\mathrm{TTR}+\mathrm{HA}$ & $-2.44(0.52)$ & $.0002^{3}$ & 3.03 & $5.08(0.59)$ & $.0012^{3}$ & 3.03 & $7.20(0.44)$ & $.029^{3}$ & 6.87 \\
\hline $\mathrm{TTR}+\mathrm{SA}$ & $-7.25(1.84)$ & $N S^{3}$ & 84.4 & $3.15(1.09)$ & $N S^{3}$ & 11.5 & $4.87(0.65)$ & $N S^{3}$ & 34.5 \\
\hline
\end{tabular}

${ }^{1}$ relative to GAPDH, mean (SD) $\triangle C T$ of 8 pools with 2 mice per pool for Naïve and 12 pools with 2 mice per pool for all 4 treatment groups.

$P$-values: ${ }^{2}$ Acute or TTR vs Naive; ${ }^{3} \mathrm{TTR}+\mathrm{HA}$ or TTR+SA vs TTR;

${ }^{4}$ Fold Changes are relative to Naive

NS, not significant

chondrogenic genes remained elevated in the meniscus/ synovium pool whereas in the TTR+HA group (Table 3), chondrogenic gene expression was much lower and only minimally above that seen in the naïve joints. Saline injection (Table 3 TTR+SA) did not, however, reduce chondrogenic gene expression in this tissue pool to naïve levels. TGFbeta 1 treatment alone (Table 3 Acute) activated Colla1 and Col5a1 expression (102-fold and 4.08fold respectively), but there was no effect on Col3a1 expression. For the TTR group, the expression of all three fibrogenic collagen genes was markedly enhanced (15- to 30-fold), much as observed for these genes in cartilage/subchondral bone from the same group. HA, but not saline injection, decreased expression of all fibrogenic genes in the meniscus/synovium tissue pool to essentially naïve levels (Table 3 TTR+HA).

Effect of HA injection on the abundance of chondrogenic and fibrogenic proteins in the perimeniscal synovium

In naïve joints, the synovial lining and stromal cells showed staining for aggrecan and collagen types I, II and III but not collagen type V (Figure 6). Consistent with the activation of gene expression (Table 3), the TGFbeta1-induced hyperplastic lining (L) showed a strong staining for aggrecan and collagen type II (Figure $6 \mathrm{~A}$, Acute). The hyperplastic stromal cell population and its associated matrix also stained for collagen type II, but only weakly for aggrecan. The fibrotic tissues in the synovium that developed in the TTR group were also positive for aggrecan and collagen type II (Figure 6A, black arrow heads), with the latter being particularly strong in the extracellular matrix at the synovial/meniscal interface. In the HA injected joints (TTR+HA) both, cells and matrix in the synovial lining stained strongly for both collagen type II and aggrecan, but in keeping with reduced gene expression (Table 3 ) only a few cells in the restored adipose tissue-rich stroma showed the presence of these two matrix proteins, closely resembling the staining pattern of the naive stroma (Figure 6A).

Staining for fibrogenic collagens III and V was slightly enhanced in the hyperplastic lining cells; however, the 102-fold acute activation of expression of Col1a1 (Table 3) was not seen as enhanced staining for collagen type I in synovium (Figure 6B, Acute) or menisci (data not shown), suggesting that Col1a1 transcripts are inefficiently translated or that the newly synthesized protein may not be efficiently cross-linked and incorporated into synovium, but instead diffuse into the synovial fluid.

As expected, the fibrotic tissue deposits seen in the perimeniscal synovium of the TTR group were robustly stained for collagen type III, and to a lesser extent collagen type I, which was mostly concentrated at the meniscus/ synovium interface, just like aggrecan and collagen type II (Figure 6A). The vascular elements present in TTR samples (Figures 4A and 6) also stained positive for collagen type III and V but in the TTR+HA group, all three fibrogenic proteins were found only in the synovial cells. Further, the alterations in staining for collagen type III and $\mathrm{V}$ in these samples were consistent with the observed decrease in fibrogenic gene expression (Table 3).

\section{Effect of HA injection on the expression and abundance of ADAMTS5 and MMP13 in cartilage/subchondral bone and meniscus/synovium}

The metalloproteinases ADAMTS5 and MMP13 are investigated widely due to their apparent central role in murine OA $[16,30]$, and perhaps in human OA $[18,31]$. Expression of both Adamts5 (Table 4) and Mmp13 (Table 5) was detectable in both tissue pools for naïve mice, and the expression of both was increased markedly in cartilage/subchondral bone (approximately 6-fold) and meniscus/synovium (approximately 50-fold) in the TTR group, consistent with tissue remodeling. Notably, HA injection (TTR+HA), essentially maintained the low expression levels of both mmp13 and Adamts 5 at the low levels seen in the naïve tissues, whereas saline injection $(T T R+S A)$ was clearly ineffective in this regard.

Immunolocalization of ADAMTS5 in naïve joints showed that it was abundant in a chondrocyte-associated form (but not in matrix) throughout the articular cartilage and also in the synovial lining layer cells and matrix (Figure 7, Naive). This is in keeping with our studies on 


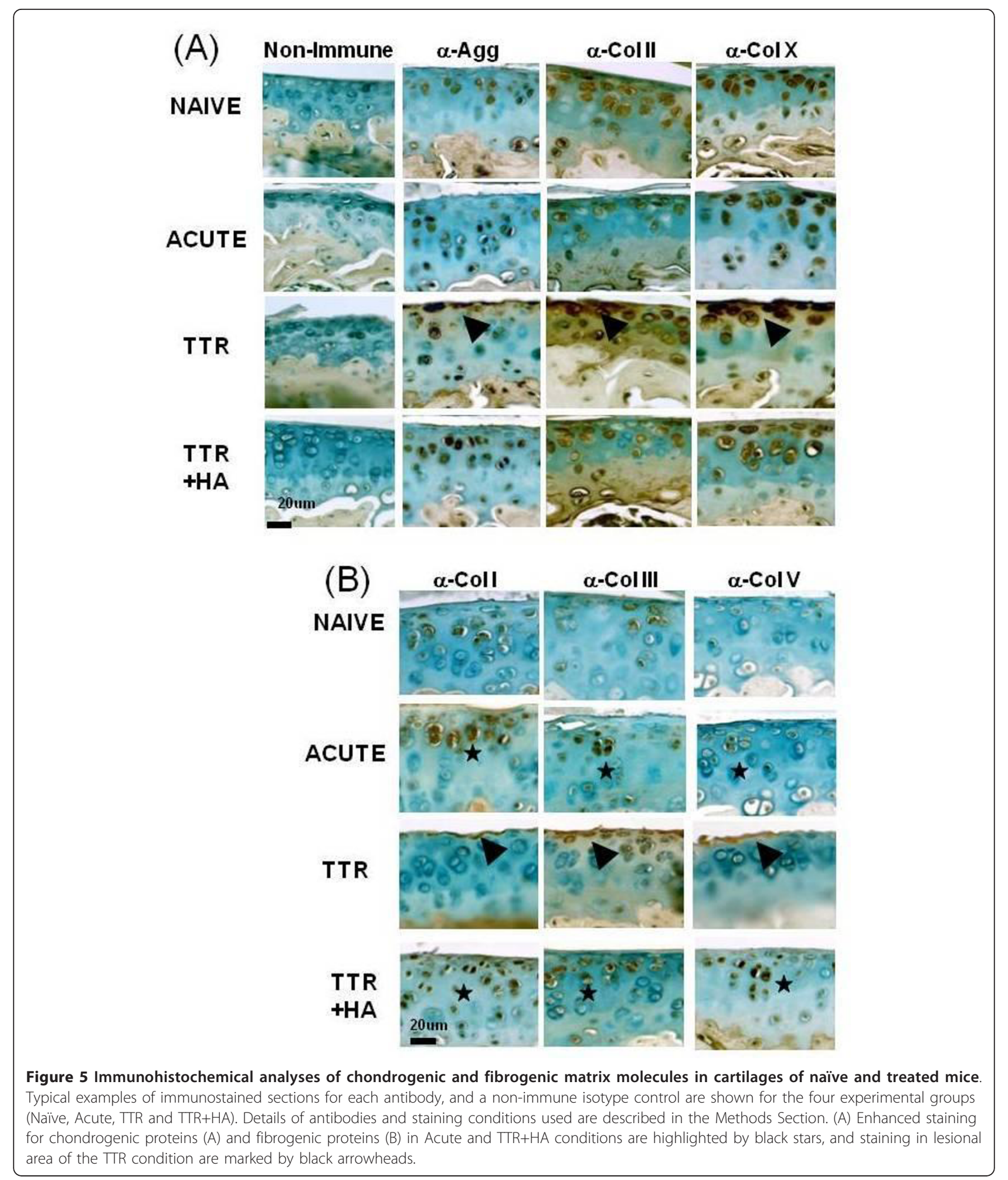

human cartilages where the enzyme was confined to the pericellular matrix, and in association with HA [27]. For the TTR group, MMP13 stained strongly in chondrocytes and the surrounding matrix at the surface of the cartilage lesions, and also in the underlying subchondral bone cells. In addition, fibrotic tissue in the synovium of these joints stained positive for MMP13 (Figure 7, TTR) and this was particularly noticeable at the interface with the 
Table 3 QPCR of chondrogenic and fibrogenic gene expression in meniscus/synovium

\begin{tabular}{|c|c|c|c|c|c|c|c|c|c|c|c|c|}
\hline & $\begin{array}{l}\text { acan } \\
\Delta C T^{1}\end{array}$ & Fold $^{2}$ & $\begin{array}{l}\mathrm{col} 2 \mathrm{a} \\
\Delta \mathrm{CT}^{1}\end{array}$ & Fold $^{2}$ & $\begin{array}{r}\text { col10a } \\
\Delta \mathrm{CT}^{1}\end{array}$ & Fold $^{2}$ & $\begin{array}{l}\text { col1a } \\
\Delta \mathrm{CT}^{1}\end{array}$ & Fold $^{2}$ & $\begin{array}{l}\text { col3a } \\
\Delta \mathrm{CT}^{1}\end{array}$ & Fold $^{2}$ & $\begin{array}{l}\text { col5a } \\
\Delta \mathrm{CT}^{1}\end{array}$ & Fold $^{2}$ \\
\hline Naive & 3.28 & 1.00 & 3.73 & 1.00 & 5.50 & 1.00 & -0.21 & 1.00 & 0.05 & 1.00 & 3.46 & 1.00 \\
\hline Acute & -0.89 & 17.5 & -1.59 & 39.9 & 1.92 & 11.9 & -6.89 & 102 & -0.13 & 1.13 & 1.43 & 4.08 \\
\hline TTR & 0.79 & 5.61 & -1.41 & 35.3 & 1.35 & 17.7 & -4.90 & 25.8 & -3.66 & 13.1 & -1.40 & 29.0 \\
\hline TTR+HA & 2.99 & 1.22 & 2.63 & 2.10 & 4.76 & 1.67 & -1.45 & 2.43 & -1.11 & 2.23 & 2.12 & 2.53 \\
\hline $\mathrm{TTR}+\mathrm{SA}$ & 1.10 & 4.53 & -1.25 & 31.5 & 1.46 & 16.4 & -6.10 & 59.3 & -2.68 & 6.63 & -0.98 & 21.7 \\
\hline
\end{tabular}

${ }^{1}$ relative to GAPDH, mean (SD) $\triangle C T$ of 2 pools with 8 mice per pool for Naïve and 2 pools with 12 mice per pool for all 4 treatment groups. Values represent the average of the two pools, with the difference between duplicates being $<20 \%$ of average pool value.

${ }^{2}$ Fold Changes are relative to Naive

meniscal tissue (black arrow). As predicted from the gene expression studies (Table 5), HA injection prior to treadmill running (TTR+HA) essentially prevented the increase in MMP13 protein abundance seen in the cartilage and synovium of the TTR group. IHC for ADAMTS5 showed that in the TTR group there was a markedly enhanced pericellular staining associated with both flattened cells lining cartilage lesions and underlying cell groups (Figure 7, TTR, black arrow heads). In addition, both cells and matrix were stained throughout the fibrotic regions of the synovium. HA injection before treadmill running (TTR+HA) essentially prevented the increased staining for ADAMTS5 of chondrocytes, and their associated matrix at the cartilage surface. It was notable that for TTR+HA samples, the synovial lining cells and stromal cells in the adipose tissue maintained strong staining for ADAMTS5, whereas mRNA levels in the relevant meniscus/synovium samples were reduced (Table 3).

Lastly, while no statistical evaluation of the meniscus/ synovium data (Tables 2, 3 and 5) was possible, the conclusions were based on the following considerations. First, the differences in gene expression between the TTR (or TTR + saline) group and the TTR+HA group was always very marked, being about 4 -fold (Acan),16-fold (Col2a1),10-fold (Col10a1),15-fold (Col1a1),4-fold (Col3a1),10-fold (Col5a1),10- to 40-fold (Adamts5) and 10 - to 30 -fold (Mmp13). This makes it highly likely that the differences found in tissues pooled from 8 to 12 mice are biologically relevant to the effects of HA. In addition, as described repeatedly in the text above, the changes in expression for each gene evaluated were often supported by changes seen in abundance of the equivalent proteins by IHC.

Effect of HA injection on the macroscopic pathology seen in CD44 knockout mice

While studies with neutralizing CD44 antibodies have implicated CD44 in the inhibitory effects of HA on expression of metalloproteinases by chondrocytes and synoviocytes [19-22], it has also been shown with isolated fibroblasts that their transition to myofibroblasts, a feature of fibrotic remodeling, is modulated by the interaction of CD44 with HA [32]. Since enhanced expression of metalloproteinases and fibrotic remodeling was also seen in joint tissues after TTR, and this was reversed by HA in vivo, we decided to further examine the need for CD44 in the protective effects of HA injection. For this purpose we subjected $C d 44-/$ - mice [17] to the TTR model and examined the extent to which HA injection was joint protective in the absence of CD44. The macroscopic pathologies seen (Figure 8) clearly indicated that CD44 was essential for the HA effects, suggesting that the binding of the injected HA to cell surface CD44 is essential for its cartilage protection and anti-fibrotic activities in this murine OA model.

\section{Discussion}

The mechanism by which injected HA exerts CD44dependent anti-fibrotic effects in murine OA appears related to the finding [33] that the fibroblast to myofibroblast transition in progressive murine lung fibrosis is also modulated by HA in a CD44-dependent fashion. In a similar way, it has been shown [34] that HA exhibits a CD44dependent protection against LPS-induced murine sepsis by binding to TLR 4 and blocking excessive inflammatory cytokine production. In this context, we set out to determine whether the cartilage-protective effects of intraarticular HA operate thru a CD44-dependent modulation of the chondrogenic/fibrogenic gene response pathways and/or thru changes in the expression of the critical metalloproteinases, ADAMTS5 and MMP13. Based on the finding that cartilage degradation in the TTR model follows the formation of fibrotic tissue deposits, we hypothesized that it would be associated with the high expression of fibrogenic genes, relative to chondrogenic, and that HAmediated protection would operate through a reversal to high chondrogenic expression.

To summarize the results (Table 6), we found that in the acute phase of the model (Days 0 to 5), and before evidence of any cartilage lesions, there was a generalized increase in expression of both chondrogenic and fibrogenic genes in both tissue compartments (presumably a direct anabolic response to TGFbeta1 injection). After 


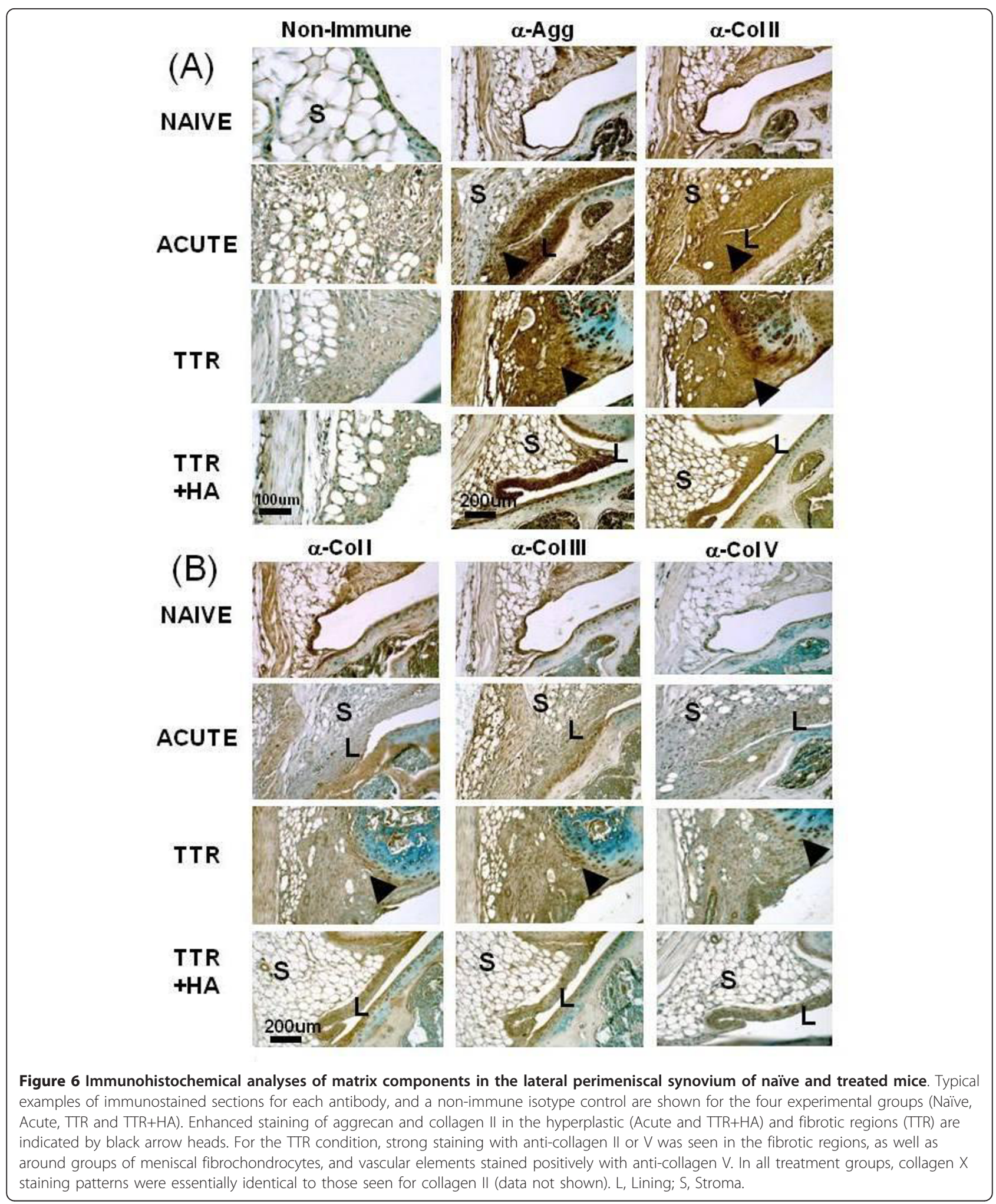

TTR, and in the presence of tissue fibrosis and cartilage erosion, the chondrogenic genes in both tissue compartments had essentially normalized to naïve levels, except for Col2a1 and Col10a1, which remained elevated in the meniscus/synovium. At the same time, the fibrogenic genes in both tissue compartments remained elevated or 
Table 4 QPCR of Adamts5 expression in cartilage/ subchondral bone and meniscus/synovium

\begin{tabular}{rccccc}
\hline & \multicolumn{2}{c}{ CARTILAGE/SC BON } & \multicolumn{2}{c}{ MENISCUS/SYNOVIUM } \\
& Adamts5 & $\boldsymbol{P}$ & Fold $^{5}$ & Adamts5 & Fold $^{5}$ \\
& $\boldsymbol{\Delta \mathbf { C T } ^ { 1 }}$ & & & $\boldsymbol{C C T}^{\mathbf{1}}$ & \\
\hline Naive & $8.85(0.55)$ & & $\mathbf{1 . 0 0}$ & 8.31 & $\mathbf{1 . 0 0}$ \\
TTR & $5.94(0.44)$ & $.0017^{\mathbf{3}}$ & $\mathbf{7 . 5 1}$ & 1.90 & $\mathbf{8 5 . 1}$ \\
TTR+HA & $7.56(0.86)$ & $.041^{4}$ & $\mathbf{2 . 4 4}$ & 5.35 & $\mathbf{7 . 8 4}$ \\
TTR+SA & $6.22(1.24)$ & $.009^{4}$ & $\mathbf{6 . 2 0}$ & -0.17 & $\mathbf{3 5 7}$ \\
\hline
\end{tabular}

'relative to GAPDH, mean (SD) $\triangle C T$ of 8 pools with 2 mice per pool for Naive and 12 pools with 2 mice per pool for all 4 treatment groups.

${ }^{2}$ relative to GAPDH, mean (SD) $\triangle C T$ of 2 pools with 8 mice per pool for Naïve and 2 pools with 12 mice per pool for all 4 treatment groups. Values represent the average of the two pools, with the difference between duplicates being $<20 \%$ of average pool value. $P$-values: ${ }^{3} T R$ vs Naive; ${ }^{4} T R$ +HA or TTR+SA vs TTR

${ }^{5}$ Fold Changes are relative to Naive

even increased further, particularly in the cases of Col3a1 and Col5a1. In addition, the expression levels of both Adamts5 and Mmp13 were markedly increased in both tissue compartments in the TTR model. These results are consistent with the idea that cartilage degradation is due to a high expression of fibrogenic genes relative to chondrogenic genes, and also due to a high expression of the metalloproteinases known to be involved in the degradative cascade.

Most importantly, in terms of understanding the mechanism of HA-mediated protection, it was found that HA injection resulted in activation (relative to saline injection) of chondrogenic genes in the cartilage/subchondral bone and a diminution of fibrogenic genes in both tissue compartments. Further, HA injection resulted in a normalization of expression of Adamts5 and Mmp13 in both compartments. These results indicate that HA-mediated protection is due to a repression of fibrogenesis and an enhancement of chondrogenesis in the cartilage/subchondral bone along with a lowering of the expression of the relevant metalloproteinases in both compartments.

Table 5 QPCR of mmp13 expression in cartilage/ subchondral bone and meniscus/synovium

\begin{tabular}{|c|c|c|c|c|c|}
\hline & \multicolumn{3}{|c|}{ CARTILAGE/SC BONE } & \multicolumn{2}{|c|}{ MENISCUS/SYNOVIUM } \\
\hline & mmp13 & $P$ & Fold $^{5}$ & mmp13 & Fold $^{5}$ \\
\hline & $\Delta \mathrm{CT}^{1}$ & & & $\Delta \mathrm{CT}^{1}$ & \\
\hline Naive & $4.74(0.9)$ & & 1.00 & 14.10 & 1.00 \\
\hline TTR & $1.95(1.01)$ & $.004^{3}$ & 5.73 & 9.56 & 23.3 \\
\hline $\mathrm{TTR}+\mathrm{HA}$ & $3.50(1.11)$ & $.045^{4}$ & 1.95 & 13.15 & 1.93 \\
\hline $\mathrm{TTR}+\mathrm{SA}$ & $1.12(0.75)$ & $.003^{4}$ & 12.30 & 7.89 & 74.4 \\
\hline
\end{tabular}

${ }^{1}$ relative to gapdh, mean (SD) (Delta symbol) CT of 8 pools with 2 mice per pool for Naïve and 12 pools with 2 mice per pool for all 4 treatment groups. ${ }^{2}$ relative to gapdh, mean (SD) (Delta symbol) CT of 2 pools with 8 mice per pool for Naïve and 2 pools with 12 mice per pool for all 4 treatment groups. Values represent the average of the two pools, with the difference between duplicates being $<20 \%$ of average pool value. $p$ values: ${ }^{3} T R$ vs Naive; ${ }^{4} T R R$ $+\mathrm{HA}$ or $\mathrm{TTR}+\mathrm{SA}$ vs $\mathrm{TTR} ;{ }^{5}$ Fold Changes are relative to Naive.
At the histological level, (Figure 6), when TTR samples are examined together with the naïve and acute sections, it is apparent that TGFbeta1 treatment alone results in the appearance of cells with a fibrogenic pericellular/cell-associated matrix, and that during the biomechanical challenge of treadmill running, this cell population is markedly diminished as the surface layer is eroded. However, when $\mathrm{HA}$ is injected before treadmill usage (TTR+HA), the fibrogenic pool of cells and associated matrix remains intact. Taken together, the data suggest that HA prevents the catabolic response of chondrocytes which are surrounded by a fibrogenic ECM. In this context, treadmill running alone for 14 days results in only minimal cartilage thinning on the femoral condyles [26] and, although treadmill alone stimulates Col1a1 (approximately four-fold) and Col2a1 (approximately seven-fold) expression (but not other collagens), this did not cause a detectable accumulation of fibrogenic collagens in the pericellular/cell-associated space (data not shown). It is likely that cartilage erosion in this model is ultimately driven by "catabolic" soluble mediators and one possible source is the mixture of cell types of the remodeled synovial lining. In this context Hematoxylin/Eosin histology of the perimeniscal synovium (Figure 4) showed that HA prevented both fibrotic remodeling and neovascularization, in keeping with the observed inhibition of profibrotic gene expression (Table 3). An associated effect of HA during treadmill running is inhibition of TGFbeta1-induced chondrogenic gene induction in the synovium/meniscus (Table 3), which suggests that the elimination of both fibrotic and chondrogenic cells might promote restoration of the homeostatic adipose-rich stroma of the synovium.

It should be noted that with respect to changes in gene expression, the results were obtained with samples containing more than one type of tissue. In one case it was tibial and femoral cartilage with attached subchondral bone, and in the other it was the lateral and medial menisci with attached synovium. It is, therefore, not possible to discern which cell-types were most affected at the gene expression level by the injection of hyaluronan. However, the immunohistochemical studies did illustrate that in most cases all tissues exhibited protein changes consistent with the alterations in gene expression observed.

A more mechanistic insight into the effects of HA injection seen in this study is suggested by our studies with Cd44-/- mice (Figure 8). We have previously reported that CD44, together with pericellular aggrecan and HA can act as a potent inhibitor of profibrogenic TGFbeta1 signaling in dermal wound healing [17]. This could at least in part be explained by a shift from an ALK5/SMAD2,3 (fibrogenic) to an ALK1/SMAD1,5,8 (chondrogenic) signaling response. The requirement for CD44 in HA-mediated protection from joint degradation in this OA model indicates that the injected HA interacts with cell surface CD44 and, 


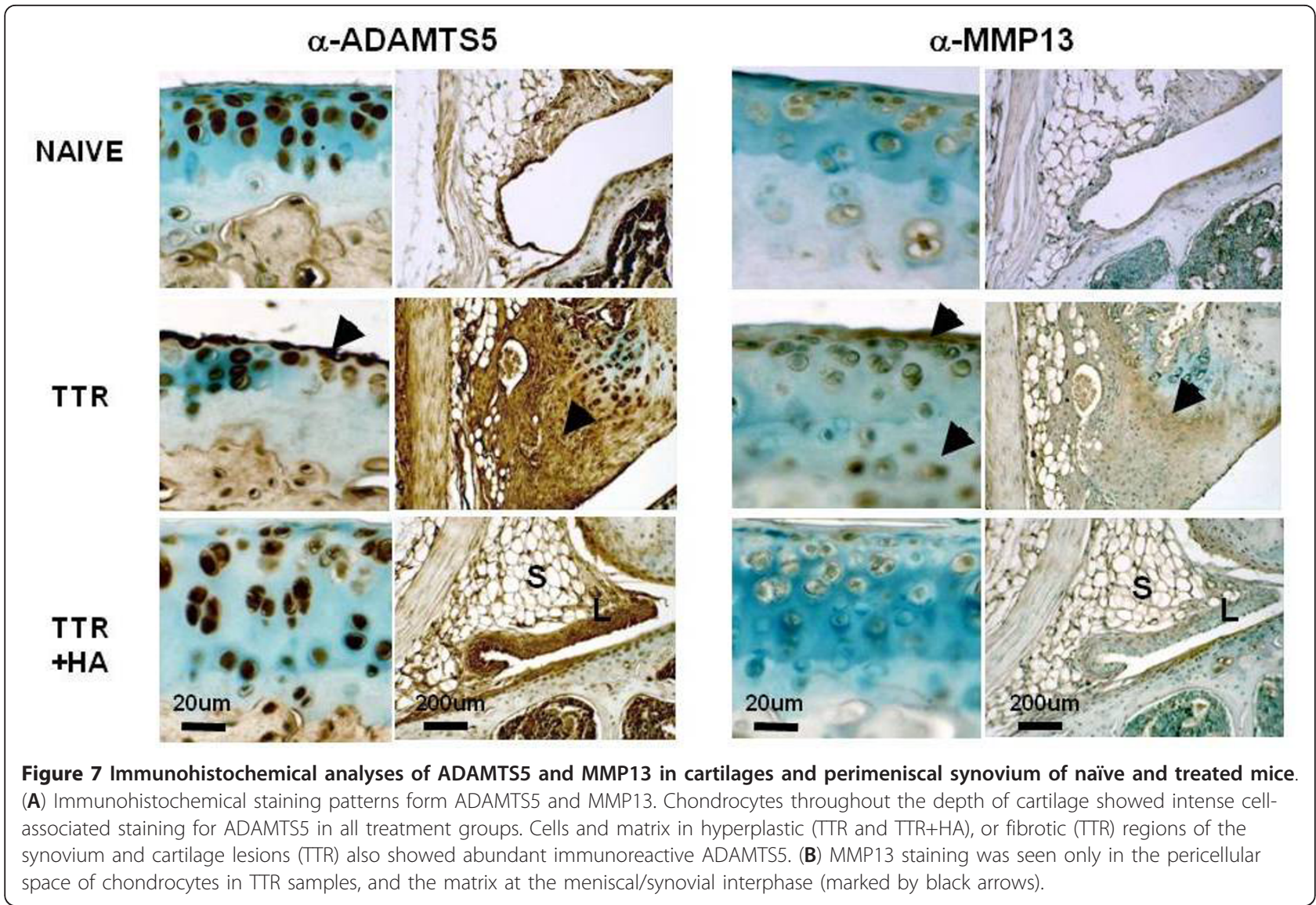

thereby, mediates a switch from fibrogenesis to chondrogenesis in the cartilage and adipogenesis in the activated stromal cell population (Figure 4). This hypothesis is strengthened by the knowledge that chondrogenesis and adipogenesis are known to be promoted by strong BMP/ ALK1/Smad1/5/8 signaling [35].

\section{A proposed molecular mechanism for joint protection by HA}

The current study shows that HA injection, when used soon after a joint insult, can inhibit the cascade of OA-like changes which occur in the cartilage/subchondral bone and meniscus/synovium (the data are summarized in Table 6). This protective effect of HA has also been demonstrated convincingly in a range of other animal models of OA $[3-7,36]$. However, uncovering the central process by which HA operates will clearly require further work to delineate its effects on the fate of proliferated synovial stromal cells and also on soluble mediator production during biomechanical stimulation. For example, HA may prevent the CD44-dependent transition of TGFbeta1-activated stromal cells to a stable myofibroblastic phenotype, much as demonstrated in human fibroblast differentiation $[37,38]$. Indeed, such a process might prevent the appearance of contractile myofibroblasts in human OA cartilage [39]. In addition, HA may reduce apoptosis [40], which in turn could reduce fibrotic remodeling by modulating innate immune responses, as shown for alveolar epithelial cells in lung fibrosis [41].

\section{Conclusions}

We speculate that any beneficial effects of HA injection on pain and function in OA patients [1] result from a normalization of the synovial content of pro-inflammatory and pro-catabolic mediators, which appear to be responsible for cartilage erosion in human OA [42-45]. Such a pathway is consistent with the finding that patient benefit from HA injection appears to depend on the stage and/or sub-type of OA being treated $[1,46,47]$. Since the therapeutic effects of HA injection described here, and elsewhere, appear to depend largely on its antifibrotic activity it is possible that the combined use of $\mathrm{HA}$ and an anti-fibrotic agent might improve efficacy. In this regard, it is probably relevant that dosing of rats with GW788388, an agent which has anti-fibrotic effects through inhibition of ALK5, also results in excessive cartilage matrix deposition in the growth zone [48]. Indeed, this is consistent with our suggestion [49] that inhibition of ALK5 in joint progenitor cells will result in a switch from degenerative fibrosis to reparative chondrogenesis 

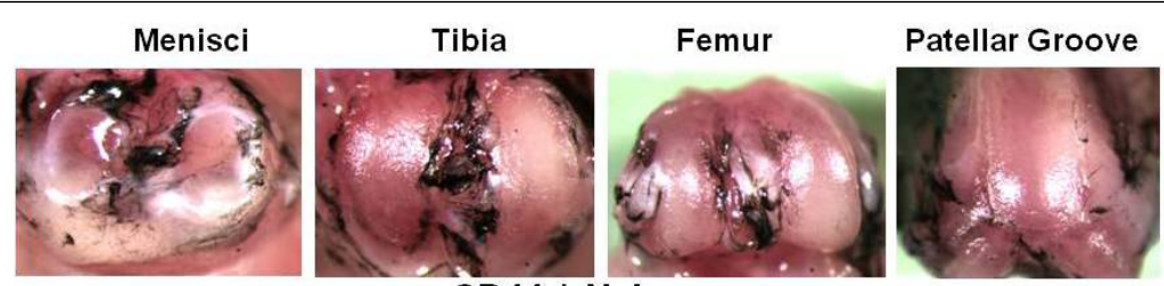

CD44-/-Naive
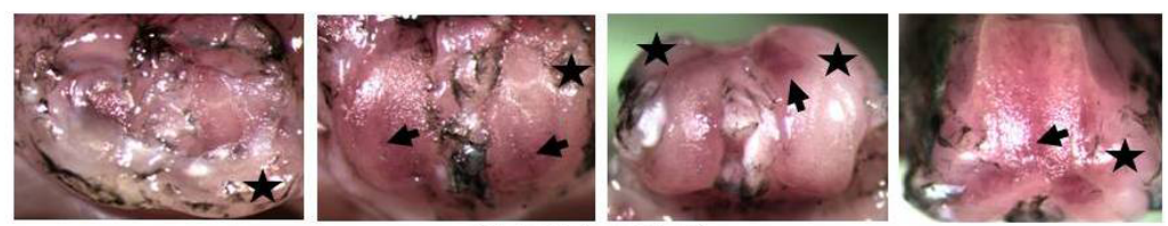

CD44-/- + TTR
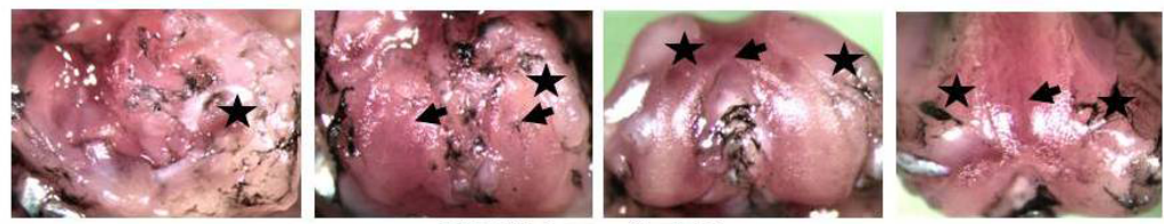

\section{CD44-/-+TTR+HA}

Figure 8 Menisci and cartilage surfaces of Cd44-/- mice show lack of protection by intra-articular HA injections. Cd44-/- male mice were subjected to the TTR model without $(n=4)$ or with $(n=4)$ intra-articular HA injections. Knee joints from those treated mice as well as naïve $(n$ $=4)$ treated mice were examined by India Ink application, photography under a Nikon dissecting microscope (SMZ1000, X6) and images processed with Spot Basic, Diagnostic Instruments, Inc. Typical images of meniscus and cartilage surfaces from naïve joints (top row) and joints from the TTR group (second row) and TTR+HA group (third rows) are shown. Black arrow heads indicate cartilage erosion and black stars indicate fibrotic overgrowth. See Figure 2 for equivalent images from wild-type mice.

Table 6 Summary of tissue changes in the TTR model illustratesthe therapeutic effects of HA injection.

\begin{tabular}{|c|c|c|c|}
\hline & $\begin{array}{c}\text { TTR } \\
\text { Relative to Naive }\end{array}$ & $\begin{array}{c}\text { TTR+HA } \\
\text { Relative to TTR }\end{array}$ & $\begin{array}{c}\text { TTR+Saline } \\
\text { Relative to TTR }\end{array}$ \\
\hline \multicolumn{4}{|c|}{ CARTILAGE/SUBCHONDRAL BONE } \\
\hline Erosion & $+++^{1}$ & $-{ }^{1}$ & Unchanged \\
\hline Chondrogenic Genes & Unchanged & +++ & Unchanged \\
\hline Fibrogenic Genes & +++ & - & Unchanged \\
\hline MMP Genes & +++ & - & + \\
\hline \multicolumn{4}{|l|}{ SYNOVIUM/MENISCUS } \\
\hline Perimeniscal Synovitis & +++ & - & Unchanged \\
\hline Chondrogenic Genes & +++ & - & Unchanged \\
\hline Fibrogenic Genes & +++ & - & Unchanged \\
\hline MMP Genes & +++ & - & + \\
\hline
\end{tabular}

${ }^{1}+/-=2$ - to 4 -fold Increase/decrease; $++/-=2$ - to 4 -fold Increase/decrease; $+++/-=5$ - to 10 -fold increase

in the articular cartilage. Finally, the lack of protection of HA against macroscopic OA pathology in the Cd44-/mouse, provides the opportunity to examine in future experimentation, which cell types are primarily involved in the HA-CD44 mediated therapeutic responses in the knee joint in this murine OA model.

\section{Abbreviations}

ACLT: anterior cruciate ligament transection; ADAMTS5: A Disintegrin and Metalloproteinase with Thrombospondin Motifs 5; EDTH:

ethylenediaminetetraacetic acid; FITC: fluorescein isothiocyanate; HA: hyaluronan; MMP13: matrix metalloproteinase 13; MSCs: bone marrow derived mesenchymal stem cells; OA: osteoarthritis; PBS: phosphate-buffered saline; SA: saline; SC: subchondral; TTR: TGFbeta 1 injection with treadmill running model of murine $O A$. 


\section{Acknowledgements}

We acknowledge research funding from Seikagaku Corporation and the $\mathrm{NIH}$ (R01AR057066). We thank Dr. Carla Scanzello for critical reading of the manuscript prior to submission.

\section{Author details}

'Department of Internal Medicine (Rheumatology), Rush University Medical Center, 1611 West Harrison Street Suite 510, Chicago, IL 60612, USA. ${ }^{2}$ Department of Biochemistry Rush University Medical Center, 1735 W Harrison Street, Chicago, IL 60612, USA. ${ }^{3}$ School of Physical Therapy, Carrol Hall, 421, Regis University 3333 Regis Blvd., Denver, CO 80221, USA. ${ }^{4}$ Pharmaceuticals Information Group, Seikagaku Corporation, Marunouchi Center Building 6-1, Marunouchi 1-chome Chiyoda-ku Tokyo 100-0005, Japan.

\section{Authors' contributions}

$J L$ performed mouse colony breeding and maintenance, treadmill running, tissue harvests, histological processing, staining and immunohistochemistry. DJG performed all QPCR analyses, data calculation and interpretation. WA performed experiments to determine in vivo clearance of FITC-Supartz. JV developed quantitative RNA extraction methods for cartilage/subchondral bone and meniscus/synovial membrane. JDS performed all statistical analyses of data and manuscript preparation. JT provided input on the overall experimental design with regards to experimental groups and mouse numbers and provided technical expertise on Hyaluronan preparations supplied for this study. AP provided the overall experimental design, performed intraarticular injections, and was responsible for data evaluation, interpretation and manuscript preparation. All authors have read and approved the final manuscript.

\section{Authors' information}

AP holds the Katz-Rubschlager Presidential Chair in Osteoarthritis Research at Rush University Chicago, IL.

\section{Competing interests}

JL, DJG, WA, JV and JDS declare no competing interests. AP has received research funding for this study from Seikagaku Corporation. At the time of submission, JT was a full-time employee at Seikagaku Corporation and holds no stocks and shares in the company. Seikagaku Corporation has provided research funding including payment of the article processing fee.

Received: 20 March 2012 Revised: 22 May 2012

Accepted: 21 June 2012 Published: 21 June 2012

\section{References}

1. Bellamy N, Campbell J, Robinson V, Gee T, Bourne R, Wells G: Viscosupplementation for the treatment of osteoarthritis of the knee. Cochrane Database Syst Rev 2006, CD005321.

2. Kikuchi T, Yamada H, Shimmei M: Effect of high molecular weight hyaluronan on cartilage degeneration in a rabbit model of osteoarthritis. Osteoarthritis Cartilage 1996, 4:99-110.

3. Ando A, Hagiwara Y, Chimoto E, Hatori K, Onoda Y, Itoi E: Intra-articular injection of hyaluronan diminishes loss of chondrocytes in a rat immobilized-knee model. Tohoku J Exp Med 2008, 215:321-331.

4. Zhou PH, Liu SQ, Peng H: The effect of hyaluronic acid on IL-1betainduced chondrocyte apoptosis in a rat model of osteoarthritis. $J$ Orthop Res 2008, 26:1643-1648.

5. Cake MA, Smith MM, Young AA, Smith SM, Ghosh P, Read RA: Synovial pathology in an ovine model of osteoarthritis: effect of intraarticular hyaluronan (Hyalgan). Clin Exp Rheumatol 2008, 26:561-567.

6. Smith MM, Cake MA, Ghosh P, Schiavinato A, Read RA, Little CB: Significant synovial pathology in a meniscectomy model of osteoarthritis: modification by intra-articular hyaluronan therapy. Rheumatology (Oxford) 2008, 47:1172-1178.

7. Tang T, Muneta T, Sekiya I: Fibrous change of the infrapatellar fat pad due to strenuous running exercise and its treatment with intraarticular hyaluronan injection in a rat model. J Med Dent Sci 2008, 55:163-173.

8. Aigner T, Fundel K, Saas J, Gebhard PM, Haag J, Weiss T, Zien A, Obermayr F, Zimmer R, Bartnik E: Large-scale gene expression profiling reveals major pathogenetic pathways of cartilage degeneration in osteoarthritis. Arthritis Rheum 2006, 54:3533-3544.
9. Brew CJ, Clegg PD, Boot-Handford RP, Andrew JG, Hardingham T: Gene expression in human chondrocytes in late osteoarthritis is changed in both fibrillated and intact cartilage without evidence of generalised chondrocyte hypertrophy. Ann Rheum Dis 2011, 69:234-240.

10. Barley RD, Adesida AB, Bagnall KM, Jomha NM: Immunohistochemical characterization of reparative tissue present in human osteoarthritic tissue. Virchows Arch 2010, 456:561-569.

11. Yuan GH, Tanaka M, Masuko-Hongo K, Shibakawa A, Kato T, Nishioka K, Nakamura H: Characterization of cells from pannus-like tissue over articular cartilage of advanced osteoarthritis. Osteoarthritis Cartilage 2004, 12:38-45.

12. Furuzawa-Carballeda J, Macip-Rodriguez PM, Cabral AR: Osteoarthritis and rheumatoid arthritis pannus have similar qualitative metabolic characteristics and pro-inflammatory cytokine response. Clin Exp Rheumatol 2008, 26:554-560.

13. Leydet-Quilici H, Le Corroller T, Bouvier C, Giorgi R, Argenson JN, Champsaur P, Pham T, Maues de Paula A, Lafforgue P: Advanced hip osteoarthritis: magnetic resonance imaging aspects and histopathology correlations. Osteoarthritis Cartilage 2010, 18:, 1429-1435.

14. Nakamae A, Engebretsen L, Bahr R, Krosshaug T, Ochi M: Natural history of bone bruises after acute knee injury: clinical outcome and histopathological findings. Knee Surg Sports Traumatol Arthrosc 2006, 14:1252-1258.

15. Fink B, Egl M, Singer J, Fuerst $M$, Bubenheim M, Neuen-Jacob E: Morphologic changes in the vastus medialis muscle in patients with osteoarthritis of the knee. Arthritis Rheum 2007, 56:3626-3633.

16. Li J, Anemaet W, Diaz MA, Buchanan S, Tortorella M, Malfait AM, Mikecz K, Sandy JD, Plaas A: Knockout of ADAMTS5 does not eliminate cartilage aggrecanase activity but abrogates joint fibrosis and promotes cartilage aggrecan deposition in murine osteoarthritis models. J Orthop Res 2011, 29:516-522.

17. Velasco J, Li J, Dipietro L, Stepp MA, Sandy JD, Plaas A: Adamts5 deletion blocks murine dermal repair through CD44-mediated aggrecan accumulation and modulation of transforming growth factor \{beta\}1 (TGF\{beta\}1) signaling. J Biol Chem 2011, 286:26016-26027.

18. Kevorkian L, Young DA, Darrah C, Donell ST, Shepstone L, Porter S, Brockbank SM, Edwards DR, Parker AE, Clark IM: Expression profiling of metalloproteinases and their inhibitors in cartilage. Arthritis Rheum 2004, 50:131-141.

19. Julovi SM, Ito H, Nishitani K, Jackson CJ, Nakamura T: Hyaluronan inhibits matrix metalloproteinase-13 in human arthritic chondrocytes via CD44 and P38. J Orthop Res 2011, 29:258-264

20. Yatabe T, Mochizuki S, Takizawa M, Chijiiwa M, Okada A, Kimura T, Fujita Y, Matsumoto $H$, Toyama Y, Okada Y: Hyaluronan inhibits expression of ADAMTS4 (aggrecanase-1) in human osteoarthritic chondrocytes. Ann Rheum Dis 2009, 68:1051-1058.

21. Tanaka M, Masuko-Hongo K, Kato T, Nishioka K, Nakamura H: Suppressive effects of hyaluronan on MMP-1 and RANTES production from chondrocytes. Rheumatol Int 2006, 26:185-190.

22. Wang $C T$, Lin $Y T$, Chiang BL, Lin YH, Hou SM: High molecular weight hyaluronic acid down-regulates the gene expression of osteoarthritisassociated cytokines and enzymes in fibroblast-like synoviocytes from patients with early osteoarthritis. Osteoarthritis Cartilage 2006, 14:1237-1247.

23. Asari A, Miyauchi S, Matsuzaka S, Ito T, Kominami E, Uchiyama Y: Molecular weight-dependent effects of hyaluronate on the arthritic synovium. Arch Histol Cytol 1998, 61:125-135.

24. Brown MP, Trumble TN, Plaas AH, Sandy JD, Romano M, Hernandez J, Merritt KA: Exercise and injury increase chondroitin sulfate chain length and decrease hyaluronan chain length in synovial fluid. Osteoarthritis Cartilage 2007, 15:1318-1325.

25. Plaas A, Li J, Riesco J, Das R, Sandy JD, Harrison A: Intraarticular injection of hyaluronan prevents cartilage erosion, periarticular fibrosis and mechanical allodynia and normalizes stance time in murine knee osteoarthritis. Arthritis Res Ther 2011, 13:R46.

26. Kotwal N, Li J, Sandy J, Plaas A, Sumner DR: Initial application of EPIC- $\mu C T$ to assess mouse articular cartilage morphology and composition: effects of aging and treadmill running. Osteoarthritis Cartilage 2012.

27. Plaas A, Osborn B, Yoshihara Y, Bai Y, Bloom T, Nelson F, Mikecz K, Sandy JD: Aggrecanolysis in human osteoarthritis: confocal localization 
and biochemical characterization of ADAMTS5-hyaluronan complexes in articular cartilages. Osteoarthritis Cartilage 2007, 15:719-734.

28. Eerola I, Salminen H, Lammi P, Lammi M, von der Mark K, Vuorio E, Säämänen AM: Type $X$ collagen, a natural component of mouse articular cartilage: association with growth, aging, and osteoarthritis. Arthritis Rheum 1998, 41:1287-1295.

29. Kurth TB, Dell'accio F, Crouch V, Augello A, Sharpe PT, De Bari C: Functional mesenchymal stem cell niches in adult mouse knee joint synovium in vivo. Arthritis Rheum 2012, 63:1289-1300.

30. Little CB, Barai A, Burkhardt D, Smith SM, Fosang AJ, Werb Z, Shah M, Thompson EW: Matrix metalloproteinase 13-deficient mice are resistant to osteoarthritic cartilage erosion but not chondrocyte hypertrophy or osteophyte development. Arthritis Rheum 2009, 60:3723-3733.

31. Bui C, Barter MJ, Scott JL, Xu Y, Galler M, Reynard LN, Rowan AD, Young DA: CAMP response element-binding (CREB) recruitment following a specific $\mathrm{CpG}$ demethylation leads to the elevated expression of the matrix metalloproteinase 13 in human articular chondrocytes and osteoarthritis. FASEB J 2012, 26:3000-3011.

32. Simpson RM, Wells A, Thomas D, Stephens P, Steadman R, Phillips A: Aging fibroblasts resist phenotypic maturation because of impaired hyaluronan-dependent CD44/epidermal growth factor receptor signaling. Am J Pathol 2010, 176:1215-1228.

33. Li Y, Jiang D, Liang J, Meltzer EB, Gray A, Miura R, Wogensen L, Yamaguchi $Y$, Noble PW: Severe lung fibrosis requires an invasive fibroblast phenotype regulated by hyaluronan and CD44. J Exp Med 2011, 208:1459-1471.

34. Muto J, Yamasaki K, Taylor KR, Gallo RL: Engagement of CD44 by hyaluronan suppresses TLR4 signaling and the septic response to LPS. Mol Immunol 2009, 47:449-456.

35. Boon MR, van der Horst G, van der Pluijm G, Tamsma JT, Smit JW Rensen $P C$ : Bone morphogenetic protein 7: a broad-spectrum growth factor with multiple target therapeutic potency. Cytokine Growth Factor Rev 2011, 22:221-229.

36. Jean $Y H$, Wen ZH, Chang YC, Lee HS, Hsieh SP, Wu CT, Yeh CC, Wong CS: Hyaluronic acid attenuates osteoarthritis development in the anterior cruciate ligament-transected knee: Association with excitatory amino acid release in the joint dialysate. J Orthop Res 2006, 24:1052-1061.

37. Webber J, Jenkins RH, Meran S, Phillips A, Steadman R: Modulation of TGFbeta1-dependent myofibroblast differentiation by hyaluronan. Am J Pathol 2009, 175:148-160

38. Wight TN, Potter-Perigo $\mathrm{S}$ : The extracellular matrix: an active or passive player in fibrosis? Am J Physiol Gastrointest Liver Physiol 2011, 301:G950-955.

39. Kim AC, Spector M: Distribution of chondrocytes containing alphasmooth muscle actin in human articular cartilage. J Orthop Res 2000, 18:749-755.

40. Meran S, Luo DD, Simpson R, Martin J, Wells A, Steadman R, Phillips AO: Hyaluronan facilitates transforming growth factor-beta1-dependent proliferation via CD44 and epidermal growth factor receptor interaction. J Biol Chem 2006, 286:17618-17630.

41. Tanjore H, Blackwell TS, Lawson WE: Emerging evidence for endoplasmic reticulum stress in the pathogenesis of idiopathic pulmonary fibrosis. Am J Physiol Lung Cell Mol Physiol 2012, 302:L721-729.

42. Murray DH, Bush PG, Brenkel IJ, Hall AC: Abnormal human chondrocyte morphology is related to increased levels of cell-associated IL-1beta and disruption to pericellular collagen type VI. J Orthop Res 2010, 28:1507-1514.

43. Adams SB Jr, Setton LA, Kensicki E, Bolognesi MP, Toth AP, Nettles DL: Global metabolic profiling of human osteoarthritic synovium. Osteoarthritis Cartilage 2012, 20:64-67.

44. Helmark IC, Mikkelsen UR, Borglum J, Rothe A, Petersen MC, Andersen O, Langberg $H$, Kjaer M: Exercise increases interleukin-10 levels both intraarticularly and peri-synovially in patients with knee osteoarthritis: a randomized controlled trial. Arthritis Res Ther 2010, 12:R126.

45. Scanzello CR, McKeon B, Swaim BH, DiCarlo E, Asomugha EU, Kanda V, Nair A, Lee DM, Richmond JC, Katz JN, Crow MK, Goldring SR: Synovial inflammation in patients undergoing arthroscopic meniscectomy: molecular characterization and relationship to symptoms. Arthritis Rheum 2011, 63:391-400.

46. Lohmander LS, Dalén N, Englund G, Hämäläinen M, Jensen EM, Karlsson K, Odensten M, Ryd L, Sernbo I, Suomalainen O, Tegnander A: Intra-articular hyaluronan injections in the treatment of osteoarthritis of the knee: a randomised, double blind, placebo controlled multicentre trial. Hyaluronan Multicentre Trial Group. Ann Rheum Dis 1996, 55:424-431.

47. Navarro-Sarabia F, Coronel P, Collantes E, Navarro FJ, de la Serna AR, Naranjo A, Gimeno M, Herrero-Beaumont G: A 40-month multicentre, randomised placebo-controlled study to assess the efficacy and carryover effect of repeated intra-articular injections of hyaluronic acid in knee osteoarthritis: the AMELIA project. Ann Rheum Dis 2011, 70:1957-1962.

48. Frazier $K$, Thomas $R$, Scicchitano M, Mirabile R, Boyce R, Zimmerman D, Grygielko E, Nold J, DeGouville AC, Huet S, Laping N, Gellibert F: Inhibition of ALK5 signaling induces physeal dysplasia in rats. Toxicol Pathol 2007, 35:284-295.

49. Plaas A, Velasco J, Gorski DJ, Li J, Cole A, Christopherson K, Sandy JD: The relationship between fibrogenic TGF $\beta 1$ signaling in the joint and cartilage degradation in post-injury osteoarthritis. Osteoarthritis Cartilage 2011, 19:1081-1090.

\section{doi:10.1186/ar3887}

Cite this article as: Li et al:: Hyaluronan injection in murine osteoarthritis prevents TGFbeta 1-induced synovial neovascularization and fibrosis and maintains articular cartilage integrity by a CD44dependent mechanism. Arthritis Research \& Therapy 2012 14:R151.

\section{Submit your next manuscript to BioMed Central and take full advantage of:}

- Convenient online submission

- Thorough peer review

- No space constraints or color figure charges

- Immediate publication on acceptance

- Inclusion in PubMed, CAS, Scopus and Google Scholar

- Research which is freely available for redistribution

Submit your manuscript at www.biomedcentral.com/submit
Biomed Central 